\title{
The reporting of sustainable development goals: is the integrated approach the missing link?
}

\author{
Sara Trucco $^{1} \cdot$ Maria Chiara Demartini ${ }^{2} \cdot$ Valentina Beretta $^{2}$ D
}

Received: 22 May 2020 / Accepted: 9 December 2020 / Published online: 1 February 2021

(C) The Author(s) 2021

\begin{abstract}
This commentary argues that the integrated thinking could support the simultaneous consideration of different stakeholders' groups to ensure that the SDGs can be achieved as a whole. Prior research, indeed, has argued that social and environmental accounting should put forward actions against unsustainability. Recent literature and international bodies report action to mitigate the negative impacts of unsustainability globally, such as the introduction of the 17 Sustainable Development Goals (SDGs) to set an agenda for the implementation of sustainable development. The implementation of the SDGs has not thus far resulted in the expected outcomes, since there is a lack of focus on how to identify interdependencies among different goals. Integration in SDGs has emerged as an approach to promote actions in this regard, but only a limited number of studies have put forward how integrated reporting and thinking can support the implementation of actions and the monitoring of their progress. Therefore, a paradigm shift in the implementation of an integrated approach in monitoring sustainable development worldwide should be promoted. This could have economic, financial and business consequences; for instance, to support national development plans by creating national financing frameworks, to improve internal decision making and information for investors, to effectively engage the public in sustainability practices such as a Green New Deal and to enhance the perspective of both public and private sector. The adoption of integrated reporting (IR) can describe the value creation process of an organization, by considering the influence of the external environment, relationships, and various resources. By including the concept of sustainable development, the revised IR Framework can be translated at various levels of analysis, by helping firms, local authorities, countries, or other stakeholders in developing proper strategies to improve their process of sustainable development creation. Areas for fruitful future research can be addressed to identify those interdependencies among goals that could effectively enable the SDGs to be universal, indivisible, and interlinked. A further call for research could be focused on what interconnections in the SDGs could be developed across sectors, societal actors, and between and among low, medium, and high-income countries.
\end{abstract}

Extended author information available on the last page of the article 
Keywords Integrated reporting $\cdot \mathrm{Sdgs} \cdot$ Integrated thinking $\cdot$ Sustainability

\section{Introduction}

Social and environmental accounting (SEA) should take "challenges, problems, structures, systems, obstacles and conflicts associated with unsustainability in all its guises" (Bebbington, Russell, and Thomson 2017, p. 32) into account. Recent literature and international bodies are thus taking actions to try and identify, measure, and mitigate the negative impact of unsustainability globally (Gibbons et al. 2000). To this end, in 2015, the United Nations (UN) General Assembly issued 17 Sustainable Development Goals (SDGs), identifying 169 targets, and in this way, it set an agenda for the implementation of sustainable development worldwide (Bebbington and Unerman 2018). This could have economic, financial and business consequences (Barth et al. 2017; Lins et al. 2017; Bebbington and Unerman 2018; Bain et al. 2019; Nedopil Wang, Lund Larsen and Wang, 2020), such as supporting national development plans by creating national financing frameworks, improving internal decision making and information for investors (Barth et al. 2017), effectively engaging the public in sustainability practices such as a Green New Deal (Bain et al. 2019) and enhancing the relevance of the value creation for both public and private sectors. However, a large body of literature argues that the implementation of the SDGs will not result in the expected outcomes for a variety of reasons (Horton 2014; Le Blanc 2016; Karlsson-Vinkhuyzen, Dahl and Persson 2018). This view is summarized in a Lancet article, which states that these goals are "fairy tales, dressed in the bureaucratese of intergovernmental narcissism, adorned with the robes of multilateral paralysis, and poisoned by the acid of nation-state failure" (Horton 2014, p. 2196). Secondly, from a more practical and operational perspective, other researchers have suggested that although the SDGs provide 42 targets on "means of implementation" included in the 16 SDGs, there is a lack of focus on how to identify "interdependencies among goals" (Stafford-Smith et al. 2017, p. 912), which could effectively enable the SDGs to be "universal, indivisible and interlinked" (Sustainable Development Goals 2016, clause 71).

\section{The need for an integrated approach in implementing and reporting the SDGs}

A number of scholars have debated the need for integration from a public policy standpoint since sustainable development involves formulating strategies grounded on the assumption that local action has a global effect (Le Blanc 2016; KarlssonVinkhuyzen, Dahl and Persson 2018). Hence, international and coordinated policies are expected to produce better outcomes than local and decoupled ones. Stafford-Smith et al. (2017) posited that more interconnections in the SDGs should be developed across sectors, across societal actors, and between and among low, medium, and high-income countries. Integration between SDGs has also been conceived as a way to develop accountability both globally and at a local level 
(Karlsson-Vinkhuyzen, Dahl and Persson 2018). Thus, literature has investigated the role of integration in SDGs as an approach to plan actions to achieve sustainable development and accountability, while a limited number of studies indicate how integrated reporting may support the implementation of actions and the monitoring of their progress (United Nations 2015; United Nations Development Group 2017). Among these studies, even less research has been dedicated to the analysis of an Integrated Reporting (IR) Framework that could be applicable to different levels of analysis, from the global to the national and the corporate one. Indeed, a reporting system that adopts cascading indicators at different levels can ensure that trade-offs are reconciled by a common set of measures (United Nations 2015; United Nations Development Group 2017). Furthermore, it can also support corporations to engage more proactively with SDGs (Van Zanten and Van Tulder 2018) and to effectively produce sustainable development (Busch et al. 2016). Moreover, the types of interactions of SDGs - from indivisible to canceling-will affect how SDGs and related targets should be reported (Nilsson et al. 2016; Schmidt 2017). Therefore, adopting the IR Framework and adapting it to local specificities could help exploit interdependencies among SDGs at the company level. As argued by Le Blanc, a systemic response is required to support sustainable development (Le Blanc 2015). To this end, the SDGs and the Paris Agreement represent two steps towards this aim (Adams 2017). Despite the attention given to the development of sustainability criteria for assessing the sustainability of performance of companies and countries (e.g. Schmidheiny et al. 1997; OECD 2001; GRI 2002; AIChE 2004; IChemE 2002), aggregation is needed to ensure comparability of different entities' performance through properly integrated reporting models (Krajnc and Glavič 2005; Griggs et al. 2014; Adams 2017). In fact, the main goals, which aim at improving "social, economic and environmental issues to achieve holistic sustainability" (Madar, Subari and Baqutayan 2017, p. 312), have rapidly been embraced worldwide because the need for sustainable development has become an urgent matter for the entire world (Madar, Subari and Baqutayan 2017). However, even if a shared focus upon these issues has been agreed, there is still a lack of exploitation of synergies and trade-offs between different areas (Sachs 2012).

\section{Integrated thinking and reporting, and sustainable development goals: the missing link}

\section{Integrated thinking and reporting and the contribution to SDGs}

Some studies argued that a reporting system is expected to track progression on the achievement of the SDGs and resolve trade-offs at the same time, by adopting a weighting system that clarifies interactions and priorities (Costanza et al. 2016). In particular, the integrated thinking approach and the related Integrated Reporting Framework by the International Integrated Reporting Council (IIRC) deserve further attention in the development of an IR Framework to monitor SDGs at different levels of analysis (Adams 2017). 
Integrated Thinking has two features. The first is related to strategy, governance, past performance, and future plans to create long-lasting value (World Intellectual Capital Initiative 2013). The second is related to connecting departments, through the links among different internal units (Black Sun 2012; IIRC 2013; World Intellectual Capital Initiative 2013; Dumay and Dai 2017). Integrated Reporting supports and stimulates integrated thinking and decision-making to create value over the short and long term (Cheng et al. 2014). In particular, IR is embedded in integrated thinking. According to Churet and Eccles, IR is only the visible part of what is happening below the surface (Churet and Eccles 2014). The IR Framework clearly states that "the more that integrated thinking is embedded into an organisation's activities, the more naturally will the connectivity of information flow into management reporting, analysis and decisionmaking. It also leads to better integration of the information systems that support internal and external reporting and communication, including preparation of the integrated report" (IIRC 2013, p. 2). However, the IR, to be effective across the entire firm, needs the commitment of the top management and the efforts inside the organizations to diffuse the integrated thinking, along with the awareness of different sustainability topics and a commitment to stakeholder engagement and responsiveness (Knauer and Serafeim 2014).

On the one hand, the integrated thinking can be adopted to link each of these areas to the others and to facilitate a holistic approach (Black Sun 2012; IIRC 2013; World Intellectual Capital Initiative 2013; Dumay and Dai 2017). Despite the fact that the main novelty in the SDGs is that they can cover the whole sustainable development universe, the set of defined goals and targets does not reflect a systemic view of the mechanisms of the socio-economic engine worldwide (Le Blanc 2015). Indeed, while the political framework behind SDGs is clearly defined, this does not reflect the multiple links between different areas of interest and related stakeholders represented by different sustainable goals. Subsequently, these links may not be channeled into the international political arena or considered when designing new policies (Le Blanc 2015).

On the other hand, the IR Framework can help by exploiting the areas that are connected by strong systemic links recognized by the scientific community but that are not operationalized in goals or targets of the various SDGs. As supported by Adams, the adoption of the IR Framework for monitoring SDGs can enhance the conceptual rigor that is required when integrated thinking is adopted (Adams 2017). To this end, since according to previous studies the same SDG can contribute to creating value in different capitals, the adoption of IR can support the identification of trade-offs and synergies among different SDGs. For instance, in the social and environmental accounting literature, Adams proposed adopting the existing IR Framework to monitor SDGs to promote the inclusion of risks and opportunities related to the external environment in the decision making processes of the organizations (Adams 2017). Adams pointed out that the IR Framework can be used to aid "understanding of trade-offs across the interdependent and potentially conflicting SDGs" (Adams 2017, p. 10). Hence, the adoption of this framework would allow the identification of multi-capitals that contribute to the development, synergies and dependencies, and conflicts among SDGs (Adams 2017). Additionally, a clear identification 
of which and how SDGs are contributing to creating value for the various forms of capital has been provided in extant literature (Adams 2017).

\section{Extending the IR framework: a paradigm shift in SDG reporting?}

Despite the several benefits related to the use of the IR in sustainable development reported in previous studies (e.g. Eccles and Krzus 2010; Lai, Melloni and Stacchezzini 2016; Busco, Granà and Izzo 2018; Ghani et al. 2018), the tool needs adapting to allow its utilization at various levels of analysis. This would enable exploiting all the potentialities that may be associated with the use of the IR Framework for monitoring SDGs. In particular, studies have identified four areas that need improvements.

First, one of the main limitations associated with the actual IR Framework is that it is strictly related to the concept of value creation, with the dominance of the "economic value" (De Villiers, Rinaldi and Unerman). However, when considering the term "value creation", we should recall that the IR Framework has been introduced to report the value that is distributed to society (Brown and Dillard 2014; De Villiers, Rinaldi and Unerman 2014; Adams 2015; Flower 2015). This implies that not only economic value is the focus of the analysis. In this regard, in 2013 the IIRC introduced the concept of sustainability, intended as the efficient use of nonfinancial resources that can ensure a sustainable planet and a stable economy (IIRC 2013). To align the current IR Framework to these concepts and its adoption for SDG reporting, the term "value creation" should be re-defined to incorporate issues that are relevant to achieve sustainable development (Atkins and Maroun 2018).

Second, while according to the original focus (e.g. the stakeholder-inclusive characteristics of GRI G4), the IR Framework was addressed to the broad concept of stakeholders, how the IIRC framework is currently conceptualized puts more emphasis on the economic value creation, and, therefore seems to be mainly addressed to shareholders (De Villiers, Rinaldi, and Unerman 2014). To adapt the IR Framework to the monitoring need of sustainable development, the target audience of the framework should be more similar to the one of sustainability reports, by including actors like local authorities, government, agencies, private sector, and civil society (Stafford-Smith et al. 2017).

Third, change can be driven by public commitment, both at the individual, corporate or national level (Victor 1998; Biermann and Pattberg 2008). The actual IR Framework is not designed to detect public commitment, since it mainly adopts a firm-related perspective (IIRC 2013). However, sustainable development is not only a matter of organizations, but nations and individuals may contribute to the achievement of the defined targets, as well. Indeed, the revised IR Framework can be adapted at various levels of analysis, by helping not only firms but also local authorities, countries, or other stakeholders (e.g. in Universities; Veltri and Silvestri 2015) in developing appropriate strategies to improve their process of sustainable development creation. The IR might help to highlight the relationships among firms and the external environment. Moreover, the IR Framework helps firms to pursue 
and disclose aims, which are related not only to the firm but also to the environment and the community (Burke and Clark 2016).

By considering the value in terms of activities that can sustain and promote sustainable development, the framework should be intended for adoption at various levels of analysis. At the individual level, the SDGs have the indirect consequence of influencing how people live their lives (Kates, Parris and Leiserowitz 2005), and how they can contribute in adopting sustainable daily activities. Moreover, the way we live today affects how people will live in the future (Griggs et al. 2013). At the corporate level, Callens and Tyteca stated that "due to their central role in human activities and development, firms should play an important part in the attainment of sustainability goals" (Callens and Tyteca 1999, p. 41). The revised IR Framework for the monitoring of SDGs can be used to encourage firms to adopt sustainable practices from the planning phase (Adams 2017) and integrate them in the reporting cycle by highlighting how they can help achieve the targets. Finally, at the national level, countries have always been asked to design strategic and coordinated actions that could support sustainable development worldwide (Volkery et al. 2006). Since the IR Framework has been introduced also concerning a management accounting tool, not only as a reporting instrument (e.g. Haller and Staden 2014), by considering the value in terms of sustainable development, the revised framework can be used to define guidelines and strategies not only at the corporate level but also at national and international levels.

Fourth, some studies have investigated the role of the IR Framework in supporting SDG achievement and identified a process for the alignment of SDGs to corporate value creation, drawing on the integrated thinking approach (Adams 2017). According to this process, the first step for the preparation of an IR begins with the understanding of "sustainable development issues relevant to the organization's external environment" (Adams 2017, p. 22). This step sets the basis for the following one, aimed at defining the "sustainable development issues that influence value creation" (p. 22), which in turn addresses the third one, namely "develop strategy to contribute to the SDGs through the business model" (p. 22). "Develop integrated thinking, connectivity and governance" (p. 22) is the next step and, finally, the process ends with the preparation of the integrated report. Although straightforward in its theoretical formulation, this process seems to rely on traditional approaches to corporate sustainability, where corporations are reactive in their sustainability approach and consider responsibility for a narrow set of societal challenges (Doh and Guay 2006; Matten and Moon 2008; Van Zanten and Van Tulder 2018). In such a context, a company looks for a fit between its strategy and sustainable development by adapting the latter to the former. Approaches like this have been labeled as "SDG washing" (Nieuwenkamp 2017, p. 1), i.e. aimed at covering up modest efforts towards sustainable development (Nieuwenkamp 2017; Eccles and Karbassi 2018). To change the existing paradigm in corporate sustainability, a cultural change needs to be addressed and embraced. Thus, to effectively contribute to sustainable development, SDGs should be implemented as part of the corporate vision and mission. Former studies addressed some cases of multinational corporations that adopt such a transformational change towards sustainability, such as Philips and Unilever (Van Zanten and Van Tulder 2018), where companies adopted SDGs to reposition 
themselves and respond to sustainability challenges. Hence, what is argued here is that the IR process could start with the identification of the corporate sustainability model, i.e. the way through which the firm is willing to proactively contribute to sustainable development, and replace the business model with the sustainability model, where corporate strategy is no more merely aligned to, but inspired by SDGs.

\section{A sustainable way forward}

The number of companies that are facing sustainability issues, or at least aware of these topics, is growing (Knauer and Serafeim 2014). The implementation of sustainable development is now perceived as a key issue worldwide. To this end, 17 SDGs have been issued by the UN. To ensure reporting and monitoring of these goals, 169 specific targets have been set to be achieved by 2030 (Bebbington and Unerman 2018). Although the last goal (SDG 17) has been introduced to harmonize all the others, the adoption of integrated and systemic responses is needed to identify synergies and trade-offs among SDGs (Griggs et al. 2014; Norström et al. 2014; Le Blanc 2015) and to promote the SDG as a package, rather than the cherry-picking approach (Stafford-Smith et al. 2017). More specifically, the lack of SDGs integration has been singled out as one of the main challenges in their implementation. An isolated approach to the implementation of SDGs could result in under-exploitation of the SDGs synergies in the best case, to conflicts for the prioritization of one SDG over another, or one (a group of) country over another, or even one generation over the next in the worst case (Griggs et al. 2013). Thus, integrated action between different actors, in different sectors and countries is needed to assure that the SDG will be achieved as a whole, where integrated policy and leadership drive accountability. In this sense, the integrated thinking could support the simultaneous consideration of multiple issues when defining the value creation process both in the short and long term (Cheng et al. 2014), and, more specifically, the IR Framework proposed by the IIRC can be adopted by firms and adapted to local specificities to provide different types of information relevant to stakeholders in the same report by emphasizing the interconnections among SDGs each firm is experiencing.

This commentary contributes to advancing knowledge related to the relevance of the concept of integrated thinking in monitoring sustainable development. Notwithstanding that the IR Framework is mainly adopted at the corporate level, possible adaptations of the existing IR Framework have been proposed to allow its use at different levels of analysis for supporting the monitoring of the achievement of various SDGs.

\section{Practical advancements}

Practical contributions that can be derived from this paper might include the promotion of a paradigm shift in the adoption of the integrated approach; the description of the value creation process of an organization, by considering the influence of the external environment, relationships and various resources; and the adaptation of the 
IR Framework to the local specificities and for the operationalization of the SDG 17. There are a number of practical considerations that may be derived from this paper: we discuss these one by one in the following.

First, a paradigm shift in the adoption of the integrated approach in monitoring sustainable development worldwide should be promoted. This is in line with previous studies (e.g. Adams et al. 2016; Adams 2017), suggesting that the value creation is no longer only strictly related to the accumulation of the financial capital, but, rather, social and environmental issues are increasingly considered and, therefore, the concept of value is conceived in a much broader way. In the light of adopting the IR Framework to monitor the SDGs, the concept of value has to be clearly defined. When considering social and environmental issues, the term value is used with reference to a sustainable development concept. Therefore, creating value implies contributing to supporting sustainable development in the achievement of SDGs.

As reported in Fig. 1, the IR Framework should clearly state which sustainability model is at the core of the activity performed by different actors, such as individuals,

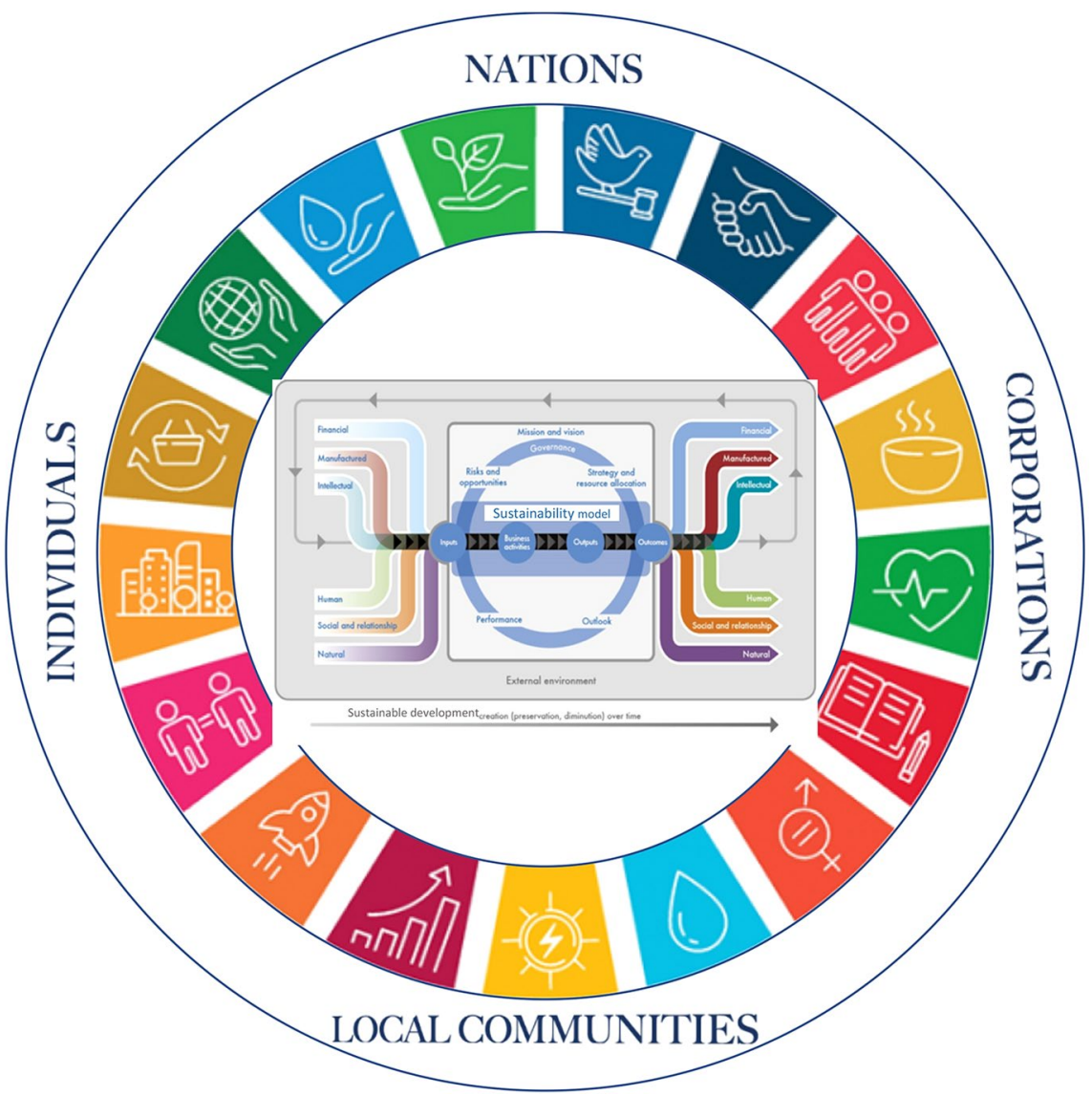

Fig. 1 IR and SDG framework 
corporations, local communities, and nations. By identifying the linkages between the entity's activity and the variation in the capitals included in the IR, the accomplishment of the targets attached to SDGs will be more easily achieved. Therefore, through this aim society as a whole will shed some light on the potential synergies and inconsistencies between SDGs, hence contributing to the implementation of the 17 SDGs.

Second, the adoption of an integrated report can describe the value creation process of an organization, by considering the influence of the external environment, relationships, and various resources (e.g. IIRC 2013). The IR Framework is a good example of monitoring SDGs, but it is advisable to focus on a broader range of stakeholders. While some studies identified the focus on the value creation for shareholders as a limit associated with IR Framework, by focusing on a variety of stakeholders, the IR Framework can adequately support the monitoring of sustainable development.

Third, by adopting the concept of sustainable development, the revised IR Framework can be adapted at various levels of analysis, by helping not only firms but also local authorities, countries, or other stakeholders (e.g. in Universities; Veltri and Silvestri 2015) in developing proper strategies to improve their process of sustainable development creation.

Fourth, an adaptation of the IR Framework could be adopted to operationalize the SDG 17. While SDGs 1 through 16 are conceived as substantive goals, SDG 17 is mainly aimed at harmonizing all of them. However, there is a general silence on how the interlinkages and interdependencies can be achieved, apart from the ambition of being universal, indivisible, and interlinked (Stafford-Smith et al. 2017). The revised framework allows the exploitation of the various interlinkages and interdependencies across targets and goals through the multi-capital approach.

\section{Theoretical advancements}

This commentary opens avenues for theoretical advancements as well. In particular, further research would be useful to present some applications of the revised IR Framework regarding one or various SDGs. More specifically, it can be used to monitor the achievement of the 169 targets over the years, at different levels of analysis, and to identify whether there are (mis)alignments across countries. Besides, previous studies did not provide a complete overview of the awareness of this integrated thinking across nations and/or at different levels of analysis. Therefore, further investigation is also needed in this area. An impression management approach can be adopted by firms to provide stakeholders with a better image of themselves (Solomon et al. 2013). However, future studies might also analyze this trend in the achievement of SDGs (Nieuwenkamp 2017). There are a number of possible research avenues that we set out in the following.

One avenue could be to investigate which "interdependencies among goals" could effectively enable the SDGs to be "universal, indivisible and interlinked" (Stafford-Smith et al. 2017, p. 912), and, more specifically, what are the possible interlinkages and interdependencies through the multi-capital approach. From a 
public policy perspective, the involvement of the formulation of strategies grounded on the assumption that local action has a global effect on sustainable development could be more deeply investigated. Considering more general perspectives, studies might be made on analyzing how interconnections in the SDGs could be developed across sectors, across societal actors, and between and among low, medium, and high-income countries. Sustainability and management accounting are ever more interconnected; nevertheless, a clearer investigation of their links is desirable. Considering the IR Framework, its implementation to different levels of analysis, from the global to the national and the corporate ones could be explored more thoroughly. Further research is needed to analyze how SDGs can be implemented into different kinds of enterprises, such as in small and medium firms. From a methodological point of view, the definition of how the indexes of each SGD could be developed can be strengthened. Finally, the linkages between corporate disclosure and SDGs could be investigated in greater depth.

Funding Open Access funding provided by Università degli Studi di Pavia. Not applicable.

\section{Compliance with ethical standards}

Conflict of interest On behalf of all authors, the corresponding author states that there is no conflict of interest.

Open Access This article is licensed under a Creative Commons Attribution 4.0 International License, which permits use, sharing, adaptation, distribution and reproduction in any medium or format, as long as you give appropriate credit to the original author(s) and the source, provide a link to the Creative Commons licence, and indicate if changes were made. The images or other third party material in this article are included in the article's Creative Commons licence, unless indicated otherwise in a credit line to the material. If material is not included in the article's Creative Commons licence and your intended use is not permitted by statutory regulation or exceeds the permitted use, you will need to obtain permission directly from the copyright holder. To view a copy of this licence, visit http://creativecommons.org/licen ses/by/4.0/.

\section{References}

Adams CA (2015) Critical perspectives on accounting the international integrated reporting council: a call to action. Crit Perspect Account 27:23-28. https://doi.org/10.1016/j.cpa.2014.07.001

Adams CA et al (2016) Exploring the implications of integrated reporting for social investment (disclosures). Br Account Rev 48(3):283-296

Adams, C. A. (2017) 'The Sustainable Development Goals, integrated thinking and the integrated report', Copyright(C) September.

AIChE (2004) Center for Waste Reduction Technologies (CWRT), Focus area sustainability metrics. http://www.aiche.org/cwrt/pdf/BaselineMetrics.pdf. Accessed 15 May 2020

Atkins J, Maroun W (2018) Integrated extinction accounting and accountability: building an ark. Acc Audit Account J 31(3):750-786

Bain PG et al (2019) Public views of the sustainable development goals across countries. Nat sustain 2(9):819-825

Barth ME et al (2017) The economic consequences associated with integrated report quality: capital market and real effects. Account Organ Soc 62:43-64. https://doi.org/10.1016/j.aos.2017.08.005 
Bebbington J, Russell S, Thomson I (2017) Accounting and sustainable development: reflections and propositions. Crit Perspect Account 48:21-34

Bebbington J, Unerman J (2018) achieving the united nations sustainable development goals: an enabling role for accounting research. Account Audit Account J 31(1):2-24

Biermann F, Pattberg P (2008) Global environmental governance: taking stock, moving forward. Ann Rev Environ Resour 33:277-294

Black Sun (2012) Understanding transformation: building the business case for integrated reporting. International Integrated Reporting Council, London

Brown J, Dillard J (2014) Integrated reporting: on the need for broadening out and opening up. Account Audit Account J 27(7):1120-1156

Burke JJ, Clark CE (2016) The business case for integrated reporting: insights from leading practitioners, regulators, and academics. Bus Horiz 59(3):273-283

Busch T, Bauer R, Orlitzky M (2016) Sustainable development and financial markets: old paths and new avenues. Bus Soc 55(3):303-329

Busco, C., Granà, F. and Izzo, M. F. (2018) Sustainable development goals and integrated reporting. Routledge.

Callens I, Tyteca D (1999) Towards indicators of sustainable development for firms: a productive efficiency perspective. Ecol Econ 28(1):41-53

Cheng $\mathrm{M}$ et al (2014) The international integrated reporting framework: key issues and future research opportunities. J Int Financ Manag Account 25(1):90-119. https://doi.org/10.1111/jifm.12015

Churet C, Eccles RG (2014) Integrated reporting, quality of management, and financial performance . J Appl Corpor Financ 26(1):56-64

Costanza R, Daly L, Fioramonti L, Giovannini E, Kubiszewski I, Mortensen LF, Pickett KE, Ragnarsdottir KV, De Vogli R, Wilkinson R (2016) Modelling and measuring sustainable wellbeing in connection with the UN sustainable development goals. Ecol Econ 130:350-355

De Villiers C, Rinaldi L, Unerman J (2014) Integrated reporting: insights, gaps and an agenda for future research. Account Audit Account J 27(7):1042-1067

Doh JP, Guay TR (2006) Corporate social responsibility, public policy, and NGO activism in Europe and the United States: an institutional-stakeholder perspective. J Manag Stud 43(1):47-73

Dumay J, Dai T (2017) Integrated thinking as a cultural control? Meditari Account Res 25(4):574-604. https://doi.org/10.1108/MEDAR-07-2016-0067

Eccles RG, Karbassi L (2018) The right way to support the sustainable development goals. https://sloan review.mit.edu/article/the-right-way-to-support-the-uns-sustainable-development-goals/. Accessed 15 May 2020

Eccles, R. G. and Krzus, M. P. (2010) One report: Integrated reporting for a sustainable strategy. John Wiley \& Sons.

Flower J (2015) The international integrated reporting council: a story of failure. Crit Perspect Account 27:1-17. https://doi.org/10.1016/j.cpa.2014.07.002

Ghani EK et al (2018) Factors influencing integrated reporting practices among Malaysian public listed real property companies: a sustainable development effort. Int J Manag Financ Account 10(2):144-162

Gibbons JW et al (2000) The global decline of reptiles, Déjà Vu Amphibians: reptile species are declining on a global scale. Six significant threats to reptile populations are habitat loss and degradation, introduced invasive species, environmental pollution, disease, unsustaina. AIBS Bull 50(8):653-666

GRI (2002) 'Sustainability Reporting Guidelines 2'. GRI [online] http://www.globalreporting.org (accessed 12 March 2015).

Griggs D et al (2013) Policy: sustainable development goals for people and planet. Nature 495(7441):305

Griggs D et al (2014) An integrated framework for sustainable development goals. Ecol Soc 19(4):49

Haller A, van Staden C (2014) The value added statement-an appropriate instrument for integrated reporting. Account Audit Account J 27(7):1190-1216. https://doi.org/10.1108/AAAJ-04-2013-1307

Horton R (2014) Offline: why the sustainable development goals will fail. Lancet 383(9936):2196

IChemE (2002) The sustainability metrics—sustainable development progress metrics recommended for use in the process industries. Institution of Chemical Engineers, Rugby

IIRC (2013) International <IR $>$ Framework.

Karlsson-Vinkhuyzen S, Dahl AL, Persson A (2018) The emerging accountability regimes for the sustainable development goals and policy integration: friend or foe? Environ Plan C Polit Space 36(8):1371-1390 
Kates RW, Parris TM, Leiserowitz AA (2005) What is sustainable development? Goals, indicators, values, and practice. Environment (Washington DC) 47(3):8-21

Knauer A, Serafeim G (2014) Attracting long-term investors through integrated thinking and reporting: a clinical study of a biopharmaceutical company. J Appl Corp Financ 26(2):57-64

Krajnc D, Glavič P (2005) A model for integrated assessment of sustainable development. Resour Conserv Recycl 43(2):189-208

Lai A, Melloni G, Stacchezzini R (2016) Corporate sustainable development: is 'integrated reporting'a legitimation strategy? Bus Strateg Environ 25(3):165-177

Le Blanc D (2015) Towards integration at last? The sustainable development goals as a network of targets. Sustain Dev 23(3):176-187

Le Blanc D (2016) Sustainable development goals and policy integration in the nexus. In: Dodds F, Bartram J (eds) The water, food, energy and climate nexus: challenges and an agenda for action. Taylor and Francis, Abingdon, UK

Lins KV et al (2017) Social capital trust, and firm performance: the value of corporate social responsibility during the financial crisis. J Financ. https://doi.org/10.1111/jofi.12505

Madar M, Subari MD, Baqutayan S (2017) Inter-institutional Framework towards Ensuring SDGs in Somaliland: transformative paradigm. RIMCIS: Revista Internacional y Multidisciplinar en Ciencias Sociales 6(3):307-329

Matten D, Moon J (2008) "Implicit" and "explicit" CSR: a conceptual framework for a comparative understanding of corporate social responsibility. Acad Manag Rev 33(2):404-424

Nedopil Wang C, Lund Larsen M, Wang Y (2020) Addressing the missing linkage in sustainable finance: the 'SDG Finance Taxonomy'. J Sustain Finance Invest. https://doi.org/10.1080/20430 795.2020.1796101

Nieuwenkamp R (2017) Ever heard of SDG washing? The urgency of SDG Due Diligence. OECD Development Matters. https://oecd-development-matters.org/2017/09/25. Accessed 15 May 2020

Nilsson M, Griggs D, Visbeck M (2016) Policy: map the interactions between sustainable development goals. Nat News 534(7607):320

Norström AV, Dannenberg A, McCarney G, Milkoreit M, Diekert F, Engström G, Fishman R, Gars J, Kyriakopoolou E, Manoussi V, Meng K, Metian M, Sanctuary M, Schlüter M, Schoon M, Schult L, Sjöstedt M (2014) Three necessary conditions for establishing effective sustainable development goals in the Anthropocene. Ecol Soc 19(3):8. https://doi.org/10.5751/es-06602-190308

OECD (2001) Corporate responsibility: private initiatives and public goals. OECD, Paris

Sachs JD (2012) From millennium development goals to sustainable development goals. Lancet 379(9832):2206-2211

Schmidheiny S, Chase R, DeSimone L (eds) (1997) Signals of change: business progress towards sustainable development. World Business Council for Sustainable Development, Geneva

Schmidt S, Neumann B, Waweru Y, Durussel C, Unger S, Visbeck M (2017) SDG 14-conserve and sustainable use the oceans, seas and marine resources for sustainable development. In: A guide to SDG interactions: from science to implementation. International Council for Science (ICSU), pp 174-218

Solomon JF et al (2013) 'Impression management, myth creation and fabrication in private social and environmental reporting: insights from Erving Goffman. Account Organ Soc 38(3):195-213

Stafford-Smith M et al (2017) Integration: the key to implementing the sustainable development goals. Sustain Sci 12(6):911-919

Sustainable Development Goals (2016) Transforming our world: the 2030 Agenda for Sustainable Development. https://sustainabledevelopment.un.org/post2015/transformingourworld. Accessed 15 May 2020

United Nations (2015) Indicators and a monitoring framework for the sustainable development goals launching a data revolution for the SDGs

United Nations Development Group (2017) Guidelines to support country reporting on the sustainable development goals

Veltri S, Silvestri A (2015) The Free State University integrated reporting: a critical consideration. J Intellect Cap 16(2):443-462

Victor DG (1998) The operation and effectiveness of the Montreal Protocol's non-compliance procedure. In: Victor DG, Raustiala K, Skolnikoff EB (eds) The implementation and effectiveness of international environmental commitments: theory and evidence. MIT Press, Cambridge, pp 137-176

Volkery A et al (2006) Coordination, challenges, and innovations in 19 national sustainable development strategies. World Dev 34(12):2047-2063

World Intellectual Capital Initiative (2013) Connectivity: Background Paper for <IR $>$. London. 
Van Zanten JA, Van Tulder R (2018) Multinational enterprises and the sustainable development goals: an institutional approach to corporate engagement. J Int Bus Policy 1(3-4):208-233

\section{Authors and Affiliations}

\section{Sara Trucco $^{1} \cdot$ Maria Chiara Demartini ${ }^{2} \cdot$ Valentina Beretta $^{2}$ D}

$\triangle$ Valentina Beretta

valentina.beretta@unipv.it

Sara Trucco

sara.trucco@unint.eu

Maria Chiara Demartini

mariachiara.demartini@unipv.it

1 Faculty of Economics, UNINT - Università degli Studi Internazionali di Roma, Rome, Italy

2 Department of Economics and Management, University of Pavia, Pavia, Italy 